\title{
Shifts and twists in the relative productivity of skilled labor
}

Citation for published version (APA):

Dupuy, A., \& Marey, P. S. (2005). Shifts and twists in the relative productivity of skilled labor.

Researchcentrum voor Onderwijs en Arbeidsmarkt, Faculteit der Economische Wetenschappen. ROA Research Memoranda No. 9E https://doi.org/10.26481/umaror.200509E

Document status and date:

Published: 01/01/2005

DOI:

10.26481/umaror.200509E

Document Version:

Publisher's PDF, also known as Version of record

\section{Please check the document version of this publication:}

- A submitted manuscript is the version of the article upon submission and before peer-review. There can be important differences between the submitted version and the official published version of record.

People interested in the research are advised to contact the author for the final version of the publication, or visit the DOI to the publisher's website.

- The final author version and the galley proof are versions of the publication after peer review.

- The final published version features the final layout of the paper including the volume, issue and page numbers.

Link to publication

\footnotetext{
General rights rights.

- You may freely distribute the URL identifying the publication in the public portal. please follow below link for the End User Agreement:

www.umlib.nl/taverne-license

Take down policy

If you believe that this document breaches copyright please contact us at:

repository@maastrichtuniversity.nl

providing details and we will investigate your claim.
}

Copyright and moral rights for the publications made accessible in the public portal are retained by the authors and/or other copyright owners and it is a condition of accessing publications that users recognise and abide by the legal requirements associated with these

- Users may download and print one copy of any publication from the public portal for the purpose of private study or research.

- You may not further distribute the material or use it for any profit-making activity or commercial gain

If the publication is distributed under the terms of Article $25 \mathrm{fa}$ of the Dutch Copyright Act, indicated by the "Taverne" license above, 


\title{
Shifts and Twists in the Relative Productivity of Skilled Labor
}

\author{
ROA-RM-2005/9E
}

A. Dupuy and P.S. Marey

Research Centre for Education and the Labour Market

Faculty of Economics and Business Administration

Maastricht University

Maastricht, August 2005 
ISBN 90-5321-421-6

Sec05.099.pdf 


\section{Contents}

Page

Abstract $\quad$ i

Acknowledgement $\quad$ i

1 Introduction 1

2 Theoretical framework 6

2.1 Technical changes in an assignment model $\quad 8$

2.2 Technical changes and the shape of the production function 15

$\begin{array}{lll}3 & \text { Empirical analysis } & 25\end{array}$

4 Conclusion $\quad 36$

$\begin{array}{ll}\text { References } & 37\end{array}$ 



\begin{abstract}
Skill-biased technical change is usually interpreted in terms of the efficiency parameters of skilled and unskilled labor. This implies that the relative productivity of skilled workers changes proportionally in all tasks. In contrast, we argue that technical changes also affect the curvature of the distribution of relative productivity. Building on Rosen's (1978) tasks assignment model, this implies that not only the efficiency parameters of skilled and unskilled workers change, but also the elasticity of substitution between skill-types of labor. Using data for the United States between 1963 and 2002, we find significant empirical support for a decrease in the elasticity of substitution at the end of the 70s followed by an increase at the beginning of the $90 \mathrm{~s}$. This pattern of the elasticity of substitution has contributed to the labor productivity slowdown in the mid 70s through the 80s and to a speedup in the 90s.
\end{abstract}

JEL Classification: J20, J31, O30 and O40.

Keywords: Assignment, SBTC, output growth, cointegration and change in regime.

\title{
Acknowledgement
}

The authors would like to thank Lex Borghans, Bertrand Candelon, Bruce Hansen, Ben Kriechel, Joan Muysken, Mark Sanders, Michael Sattinger, Bas ter Weel and participants at the 2004 North American Meeting of the Econometric Society, Providence, RI, the 2004 European Economic Association conference, Madrid, the 2004 European Association of Labour Economists conference, Lisbon, the 2003 Research Day of the Netherlands Network of Economics, seminars at SUNY at Albany, NY and MERIT, Maastricht University for helpful comments on earlier drafts of this paper. 



\section{Introduction}

The skill premium of college graduates has increased in most developed countries in the last decades and especially in the US. Since the relative supply of college graduates increased at the same time, this means that the relative demand for college graduates increased even faster than the relative supply. In the literature on wage inequality, these demand shifts in favor of skilled labor are interpreted as the ensuing effects of technical changes. Recent new technologies have increased the marginal productivity of skilled relative to unskilled labor. These productivity shifts are usually associated with changes in the relative efficiency parameters of skilled and unskilled workers (Katz and Murphy (1992)) such that it is implicitly assumed that the relative productivity of skilled workers increased proportionally in every task.

The main contribution of this paper is twofold. In the theoretical model we take a closer look at the possible effects of skill-biased technical change in the labor market, by analyzing how skill-biased technical change may affect the productivity of skilled workers relative to unskilled workers in a continuum of tasks. We show that the assignment model developed by Rosen (1978), not only offers a microfoundation for the CES production function, the workhorse model in the SBTC and growth literature, but also reveals a relationship between the elasticity of substitution across workers types and the slope of their productivity schedule across tasks. In this model, skill-biased technical change may lead to 
shifts and twists in the productivity schedule of skilled versus unskilled workers. Shifts correspond to increases in the relative efficiency parameter that are commonly associated with skill-biased technical change. Twists reflect changes in the elasticity of substitution between skilled and unskilled workers that have been absent in the skill-biased technical change literature.

The second contribution is that investigating for the stability of the parameters of a generalized Katz and Murphy (1992) framework, we show empirical evidence that the elasticity of substitution between skilled and unskilled labor has changed over time. This variability of the elasticity of substitution over time is of importance as it (twist) explains i) a significant part of the rise in the skill premium after 1977 but also ii) part of the productivity slowdown observed in the $70 \mathrm{~s}$ and $80 \mathrm{~s}$ and acceleration in the $90 \mathrm{~s}$ as the magnitude of the elasticity of substitution between inputs is directly linked to the growth rate of income per capita as already recognized in the literature on economic growth. ${ }^{1}$

This paper relates to the standard literature on skill-biased technical change (e.g. Katz and Murphy (1992)) by releasing the implicit assumption that the relative productivity of skilled workers increased proportionally in every task. In practice, indeed, new technologies will not necessarily increase the productivity

\footnotetext{
${ }^{1}$ Solow (1956) first showed that for an elasticity of substitution between labor and capital of 2 , income per head could grow forever if the saving rate $s$ were to be larger than the threshold $s=n / a^{2}$ where $n$ is population growth and $a$ is the relative efficiencies of capital. De La Grandville (1989) generalized this finding and showed that the value of the threshold was of the form: $s=n \beta(\sigma)^{\sigma /(1-\sigma)}$. More recently, Klump and de La Grandville (2000) have proved that the higher $\sigma$ the higher income per head.
} 
of skilled relative to unskilled workers equally in all tasks. There are two main arguments in favor of a more complex effect of new technologies on the relative demand for skilled labor than just relative productivity shifts. The first argument builds on the direct effect of new technologies on the demand for skilled labor. For instance, Autor et al. (2003) investigated the impact of recent technical change on the demand for skilled labor and found that although computers substitute for workers performing routine tasks, computers complement workers performing non-routine tasks: "the substitution away from routine to non-routine tasks was not primarily accounted for by educational upgrading; rather, task shifts are pervasive at all educational levels" (see Autor et al. p. 2). Although the net effect of new technologies is an increase in the demand for skilled labor, empirical evidence indicates that the demand for skilled relative to unskilled labor decreased in (non-routine) manual tasks and increased in (non-routine) cognitive tasks. The second argument, the indirect effect, builds on the organizational complementarity between new technologies and skilled labor (see Brynjolfsson (1995), Bresnahan (1999) and Bresnahan et al. (2002) and van Reenen and Caroli (2001) for instance): "Firms do not simply plug in computers or telecommunications equipment and achieve service quality or efficiency gains. Instead, firms go through a process of organizational redesign and make substantial changes to their service or output mix" (Bresnahan et al. (2002) pp. 1-2).

Both the skill-biased technical and organizational change ${ }^{2}$ arguments support

\footnotetext{
${ }^{2}$ See van Reenen and Caroli (2001).
} 
the idea that technical progress shifts the theoretical production possibility frontier out in such a way that the impact of new technologies on the demand for skilled labor is non trivial. However, technical progress in ICT has been characterized by separate phases of major qualitative changes during the last five decades ${ }^{3}$ from the mainframe/automation of the 60 s and 70 s to the $\mathrm{PC}$ and minicomputer of the $80 \mathrm{~s}$ and access to the world-wide-web in the $90 \mathrm{~s}$, each of these qualitative improvements probably inducing new organizational changes. Therefore, new technologies have probably shifted the production possibilities frontier and thereby the demand for skilled labor in different ways in the respective phases, i.e. acceleration and deceleration in the rate of shifts in the relative demand for skilled labor.

In the debate between supporters of the steady demand hypothesis (see Katz and Murphy (1992) and Card and Lemieux (2001)) and the acceleration hypothesis (see among others Bound and Johnson (1992), Krueger (1993), Berman et al. (1994), Autor et al. (1998) and Berman et al. (1998)), ${ }^{4}$ an important argument in support of the former has been that accelerating (skill-biased) technical change is difficult to reconcile with the slowdown in labor productivity growth ${ }^{5}$ that we have witnessed since the 70s (Acemoglu (2002)). The analysis of this paper also contributes to this discussion. We show that the decrease in the elas-

\footnotetext{
${ }^{3}$ Barras (1990) shows that computarization of any particular process came in phases.

${ }^{4}$ Krusell et al. (2000) also argue in favor of an acceleration in SBTC brought about by the more rapid decline in the relative price of capital equipment in the early $70 \mathrm{~s}$.

${ }^{5}$ See for instance Fischer (1988), Griliches (1994) and Kozicki (1997).
} 
ticity of substitution that we find at the end of the 70s has contributed to the slowdown in labor productivity that started in the 70 s and the increase in the 90s has contributed to the speedup in labor productivity in the 90s. Therefore, by acknowledging that skill-biased technical change has affected the elasticity of substitution, we are able to reconcile acceleration of skill-biased technical change with the productivity slowdown and subsequent acceleration.

The assignment model presented in this paper explains the productivity slowdown from the mid 70 s to the late 80 s by a decrease in the elasticity of substitution between skilled and unskilled workers that is, a increase in the comparative advantage of skilled workers in certain tasks. In that sense, the assignment model offers a point of view similar to the hypothesis first formulated by Nelson and Phelps (1966) and more recently by Greenwood and Yorokoglu (1997) that skilled workers have a comparative advantage in implementing and adopting new technologies so that technological changes are followed by a transition period during which a growing proportion of skilled workers are assigned to "new" tasks that consist of experimenting, developing and implementing routines in order to use these new technologies. This transition period is characterized by an acceleration of the demand for skilled workers (a shift when more skills are required to perform the various tasks with the new technology and a twist since the comparative advantage of skilled workers has changed) and a fast growing skill premium but a slowdown in labor productivity. In a recent paper, using quarterly data from 1979:1, Castro and Coen-Pirani (2005) have shown empirical evidence for 
a decline in the degree of capital-skill complementarity in the late 80s indicating the decline in the comparative advantage of skilled workers.

The remainder of this paper is organized as follows. In section 2 we show how technical change may affect the relative productivity of skilled versus unskilled workers in an assignment model that is consistent with a CES production function for the economy. In section 3 , after a brief discussion of the data, we investigate the stability of the parameters of the generalized Katz and Murphy (1992) equation to investigate whether shifts and twists in the relative productivity of skilled labor have occurred in the US. We draw our conclusions in section 4.

\section{Theoretical framework}

Though technical changes may affect the productivity of skilled relative to unskilled workers, it is, a priori, not necessarily true that the relative productivity of skilled workers shifts in the same direction and with the same magnitude in all productive tasks. In some tasks, skilled workers may have an even larger productivity compared to unskilled workers while the new technologies may decrease the relative productivity of skilled workers in some other tasks. This suggests that the distribution of relative productivity could be affected by technical changes in a non-trivial way. We develop an assignment model of skilled and unskilled workers to various productive tasks in order to assess the impact of new technologies 
on the distribution of relative productivity among two skill-types of workers.

General hedonic models, developed by Rosen (1974) and Lucas (1977), are very appealing to model assignment in the labor market as they incorporate both sources of heterogeneity, heterogeneity in workers' skills and heterogeneity in the skills required by the various jobs. However, a general drawback of hedonic models is that they do not give rise to closed-form solutions and even when they do, under very special properties (too restrictive in most applications, as shown by Ekeland et al. (2004)) like in Tinbergen (1956), the derivation of labor demand equations is very complicated as the type of the implicit aggregate function of production is undefined. To access and allow estimation of aggregate technology, we assume that workers can be homogeneously grouped into two skill groups, namely skilled and unskilled. Assuming two skill groups only, we enter Rosen's (1978) task assignment model and are able to work with well-known shapes of factor demand.

It is unlikely that our estimation results will be significantly affected by the assumption that workers can be homogeneously grouped into two skill groups. Heckman et al. (1998) accounted for individual heterogeneity and endogenous skill formation to construct college and high-school human capital aggregates and skill prices. From the constructed aggregates, they estimated the Katz and Murphy (1992) skill demand equation and found estimated parameters remarkably similar to those of Katz and Murphy (1992), i.e. elasticity of substitution between skilled and unskilled labor is 1.44 (1.41 in Katz and Murphy) and time 
trend $0.036(0.033)$.

\subsection{Technical changes in an assignment model}

We use Rosen's (1978) tasks assignment model to study how technical change affects the distribution of relative productivity between skilled and unskilled workers. In the model, there are two types of workers; skilled denoted $s$ and unskilled denoted $u$. Jobs refer to certain tasks and there is a continuum of tasks to be performed in order to produce output. The supply of skilled and unskilled labor, denoted $\bar{S}$ and $\bar{U}$ respectively, is assumed exogenous and perfectly inelastic to wages. ${ }^{6}$ The problem is to find an assignment of the various tasks to skilled and unskilled workers in order to maximize output, denoted $Y$. In that sense, the model focuses essentially on the demand for labor.

The analytic setting is as follows. Define a continuum of tasks by the index $v$ on $(0,1)$. Let $1 / \pi_{s}(v)$ and $1 / \pi_{u}(v)$ measure the productivity, in units of output per worker, of skilled and unskilled workers at task $v .^{7}$ Assume that the relative productivity of skilled to unskilled workers, defined by the function $q(v)=\pi_{u}(v) / \pi_{s}(v)$, is increasing in $v$ (i.e. $q^{\prime}>0$ ). The function $q(v)$ offers a

\footnotetext{
${ }^{6}$ In practice, the skill premium and the relative number of skilled workers are determined simultaneously by demand and supply. This might lead to an identification problem when estimating structural parameters using the inverse (relative) demand curve. However, controling for endogenous human capital formation both Heckman et al. (1998) and Ciccone and Peri (2005) have found estimates of the elasticity of substitution between skilled and unskilled workers "surprisingly" similar (Ciccone and Peri (2005) prefered estimate is 1.5) to that of Katz and Murphy (1992) on the same period.

${ }^{7}$ Note that, reciprocally, the demand for workers per unit of output at task $v$ is $\pi_{s}(v)$ and $\pi_{u}(v)$ for skilled and unskilled workers respectively.
} 
convenient ordering of tasks by comparative advantage. Skilled workers have a comparative advantage in cognitive tasks $v, v$ close to 1 , while unskilled workers have a comparative advantage in manual tasks $v, v$ close to 0.

Consider the following functional form:

$$
\begin{aligned}
\frac{1}{\pi_{s}(v)} & =\frac{\sigma-1}{\sigma} a_{s}(1-v)^{\frac{1}{1-\sigma}} \\
\frac{1}{\pi_{u}(v)} & =\frac{\sigma-1}{\sigma} a_{u} v^{\frac{1}{1-\sigma}}
\end{aligned}
$$

The distribution of relative productivity is then:

$$
\begin{aligned}
q(v) & =\frac{a_{s}}{a_{u}}\left(\frac{1-v}{v}\right)^{\frac{1}{1-\sigma}} \\
q^{\prime}(v) & =-\frac{1}{1-\sigma} \frac{a_{s}}{a_{u}} v^{-2}\left(\frac{1-v}{v}\right)^{\frac{\sigma}{1-\sigma}}
\end{aligned}
$$

Note that $q^{\prime}>0$ if and only if $\sigma>1$. For $\sigma>1, \lim _{v \rightarrow 0} q(v)=0$ and $\lim _{v \rightarrow 1} q(v)=+\infty$

The distribution of relative productivity depends on the relative magnitude of the parameters $a_{s}, a_{u}$ and $\sigma$. The ratio $a_{s u}=a_{s} / a_{u}$ indicates the relative productivity of skilled workers in the task $v=\frac{1}{2}$ whereas $\sigma$ determines the curvature 
of the distribution of relative productivity. In this paper, we argue that technical change affects both parameters $a_{s u}$ and $\sigma$.

To analyze the impact of technical change on the distribution of relative productivity, we therefore derive the comparative statics of the (logarithm of the) function $q(v)$.

$$
\begin{aligned}
\ln q(v) & =\ln a_{s u}+\frac{1}{1-\sigma} \ln \frac{1-v}{v} \\
\frac{\partial \ln q}{\partial \ln a_{s u}} & =1 \\
\frac{\partial \ln q}{\partial \sigma} & =(1-\sigma)^{-2} \ln \frac{1-v}{v}
\end{aligned}
$$

and with $\sigma>1$.

Suppose that between time periods $t-1$ and $t$ new technologies are implemented. These new technologies can affect the distribution of comparative advantage through $a_{s u}$ and $\sigma$ only. If $\sigma$ remains constant and $a_{s u}$ changes, the shift in relative productivity is proportional in all tasks, i.e. $\operatorname{dln} q=\operatorname{dln} a_{s u}$ independent of $v$. A $1 \%$ increase in $a_{s u}$ increases the relative productivity of skilled workers in all tasks by $1 \%$. Hence changes in the relative efficiency parameters lead to proportional shifts in the relative productivity schedule (see figure 1, panel a). Proposition 1 describes what happens if $\sigma$ changes while $a_{s u}$ is constant.

Proposition 1 If $\sigma$ decreases (increases) then the relative productivity of skilled 
workers increases (decreases) in tasks $v>\frac{1}{2}$ and decreases (increases) in tasks $v<\frac{1}{2}$

Proof. For $\sigma>1$ we have:

$$
\begin{aligned}
& >0 \text { if } v<\frac{1}{2} \\
\frac{\partial \ln q}{\partial \sigma}=(1-\sigma)^{-2} \ln \frac{1-v}{v} & =0 \text { if } v=\frac{1}{2} \\
& <0 \text { if } v>\frac{1}{2}
\end{aligned}
$$

In other words, if $\sigma$ increases (respectively decreases) while $a_{s u}$ is constant, the relative productivity of skilled workers in cognitive tasks ( $v$ close to 1 ) decreases (increases) whereas the relative productivity of unskilled workers in manual tasks decreases (increases), conform $\operatorname{dln} q=\left(\frac{1}{1-\sigma_{t}}-\frac{1}{1-\sigma_{t-1}}\right) \ln \frac{1-v}{v}$. Hence, changes in $\sigma$ lead to twists in the relative productivity schedule. ${ }^{8}$ The fixed point of the twist is given by $v=\frac{1}{2}$. (See figure 1, panel b) This task is the "technical marginal task": when the efficiency units of skilled and unskilled workers are equal, there is no comparative advantage in this task, this task is the "anybody-can-do-it-asefficiently" task.

\footnotetext{
${ }^{8} \mathrm{An}$ increase in the curvature of the distribution of relative productivity (a decrease in $\sigma$ ) increases the relative productivity of skilled workers in the tasks ranging from 0 to $\frac{1}{2}$ and decreases their relative productivity in the other tasks. Hence, the larger $\sigma$ the flatter the shape of $q(v)$. As $\sigma$ tends to infinity, the curvature of the relative productivity schedule disappears: there is equity of comparative advantage (see Willis (1986) for instance).
} 
$<$ insert figure $1>$

We argue that technical developments have not only affected the relative efficiency parameter $a_{s u}$ but also the curvature of the distribution of relative productivity, i.e. parameter $\sigma$. Jenker and Jenker (1994) provide some piece of evidence that may be consistent with twists in the distribution of relative productivity as they acknowledge that:

"The current impact of IT on skills is greater at the management and professional levels than at the operative level."

This observation corroborates Autor et al. (2003)'s argument that:

"Computers increase the share of human labor devoted to non-routine cognitive tasks by off-loading routine manual and cognitive tasks from expensive professionals."

For instance, suppose skilled workers are familiar with the concept of differential equations whereas unskilled workers are not. Then, the productivity of a skilled worker in solving differential equations is enhanced by developments in the capacity of computers whereas the productivity of unskilled workers in this task does not change. This type of technical development increases the relative productivity of skilled workers in analytical/cognitive tasks. However, new technologies may also affect the relative productivity of unskilled workers in manual tasks. Although skilled workers have more arithmetic skills, unskilled workers 
have a comparative advantage in tasks like cashier. The introduction of code-bar scanners makes arithmetic useless at the counter such that the productivity of unskilled relative to skilled workers increases in this task. ${ }^{9}$

Although the previous example clearly illustrates how new technologies can twist the relative productivity of skilled labor by increasing the productivity of the two skill types of labor in the tasks where each skill type has its comparative advantage, new technologies and organizational changes can produce the reverse twist. For instance, developing software that not only solves differential equations but also indicates when one needs to solve differential equations will increase the relative productivity of unskilled workers in tasks for which solving differential equations is necessary.

So far we focused on the effects of new technologies on the relative productivity of skilled workers. However, organizational changes that usually complement the introduction of new technologies within organizations, also affect the relative productivity of skilled workers in the various tasks. Hunter et al. (2001), for instance, provide an interesting case study of retail banks in the US. Through the 80 s, retail banks invested in mass, $\$ 60,000$ per employee, in a large variety

\footnotetext{
${ }^{9}$ The main difficulty in evaluating how new technologies have affected the relative productivity of skilled and unskilled workers in the various occupations is that the panel of occupations in the economy is itself affected by new technologies. It should be noted however, that our model does not suffer from this phenomenon. Suppose that, in 1963, we attach a job title to each of the tasks in the continuum $u$. Through the effect of technological and organizational changes the 2000 ordering of the job titles will be signifficantly different than the initial 1963 ordering. For instance, in 1963, task $u=0$ may be carpenter whereas in 2000 task $u=0$ may be NBA basketball player. Moreover some occupations might have disappeared whereas new occupations have been created.
} 
of new information technologies. The introduction of Automatic Teller Machines (ATMs), for instance, decreased considerably the costs of handling individual transactions and substituted routine tasks away from tellers. Standard SBTC theory would predict the erosion of tellers as a result of the introduction of ATMs shifting demand away from high-school graduates. In fact, between 1985 and 1995 the number of tellers in the banking sector dropped by 41,000 and by the mid-90s the Bureau of Labor Statistics suggested that this trend would even accelerate in the late 90 s. $^{10}$ However, the use of new technologies was complemented by a work reorganization that led tellers (the old job title "Teller" has been replaced by a new job title "Customer Service Representative") to take over routine tasks ${ }^{11}$ previously performed by Personal Bankers so that Personal Bankers could focus on sales exclusively. As a result, the number of employed tellers stabilized rather than dramatically decreased since the mid-90s. ${ }^{12}$ This example clearly indicates that although new technologies might twist the relative productivity of skilled workers so that skilled labor becomes more productive in their comparative advantage tasks, the organizational change that complements the introduction of the new technologies might lead unskilled workers to take over tasks previously held by skilled labor.

\footnotetext{
${ }^{10}$ Figures provided in Hunter et al. (2001), p. 406.

${ }^{11}$ For instance, changing addresses, issuing cards and adding new accounts etc. Note that these tasks are impossibly done by machines and rather easily performed by humans.

${ }^{12}$ Note that a partial explanation for the Tellers employment stabilization is a steady decrease of the average number of hours worked (see Hunter et al. (2001)).
} 


\subsection{Technical changes and the shape of the production function}

The question arises how changes in the distribution of relative productivity affect the shape of the production function in the economy. As Rosen (1978) acknowledged, the efficient assignment is such that the marginal task $\varepsilon$ with $\varepsilon \in(0,1)$ divides the spectrum of $v$ so that it is optimal to assign tasks $(0, \varepsilon)$ to unskilled workers and tasks $(\varepsilon, 1)$ to skilled workers. The unit isoquant is defined parametrically by integrating the demand for workers per unit of output, the inverse of the workers' productivity, over the spectrum of $v$ :

$$
\begin{aligned}
& \frac{U}{Y}=\int_{0}^{\varepsilon} \pi_{u}(v) \cdot d v \\
& \frac{S}{Y}=\int_{\varepsilon}^{1} \pi_{s}(v) \cdot d v
\end{aligned}
$$

where $Y$ is the output level.

Using the functional form of workers' productivity as defined in equations 1 and 2 , the unit isoquant reads as:

$$
\begin{aligned}
\frac{S}{Y} & =\frac{1}{a_{s}}(1-\varepsilon)^{\frac{\sigma}{\sigma-1}} \\
\frac{U}{Y} & =\frac{1}{a_{u}} \varepsilon^{\frac{\sigma}{\sigma-1}}
\end{aligned}
$$


Solving the system for the marginal task $\varepsilon$ such that labor market equilibrium is attained (equating exogenous supply to the demand for skilled and unskilled workers, i.e. $S=\bar{S}$ and $U=\bar{U})$, we derive the maximum output level $Y$ as:

$$
\begin{aligned}
\varepsilon & =1-\left(\frac{a_{s} \bar{S}}{Y}\right)^{\frac{\sigma-1}{\sigma}}=\left(\frac{a_{u} \bar{U}}{Y}\right)^{\frac{\sigma-1}{\sigma}} \\
& \Leftrightarrow \\
Y & =\left[\left(a_{s} \bar{S}\right)^{\frac{\sigma-1}{\sigma}}+\left(a_{u} \bar{U}\right)^{\frac{\sigma-1}{\sigma}}\right]^{\frac{\sigma}{\sigma-1}}
\end{aligned}
$$

Equation 10 reads as a CES production function. ${ }^{13}$ In the literature on labor demand, the parameter $\sigma$, indicating the curvature of the distribution of relative productivity, is usually referred to as the elasticity of substitution between skilled and unskilled workers. The larger $\sigma$ the larger the ease to substitute between skill types of workers or equivalently, the flatter the distribution of relative productivity. The indirect production function indicates that the existence of comparative advantages among workers imply imperfect substitution between the various types of workers.

The expression of the marginal task $\varepsilon$ as a function of the relative supply of skills reads as:

\footnotetext{
${ }^{13}$ In general, solving the system yields Rosen's indirect production function. Imposing workers' productivity as in equations 1 and 2 yields the CES form.
} 


$$
\begin{aligned}
\frac{\bar{S}}{\bar{U}} & \equiv \frac{S}{U}=\frac{a_{u}}{a_{s}}\left(\frac{\varepsilon}{1-\varepsilon}\right)^{\frac{\sigma}{\sigma-1}} \\
& \Leftrightarrow \\
\varepsilon & =\frac{\left(\frac{a_{s} \bar{S}}{a_{u} \bar{U}}\right)^{\frac{\sigma-1}{\sigma}}}{1+\left(\frac{a_{s} \bar{S}}{a_{u} \bar{U}}\right)^{\frac{\sigma-1}{\sigma}}}
\end{aligned}
$$

Assignment and wage inequality

We use equation 10 to derive the marginal product of skilled and unskilled labor.

$$
\begin{aligned}
\frac{\partial Y}{\partial I} & =a_{i}^{\frac{\sigma-1}{\sigma}}\left(\frac{Y}{I}\right)^{\frac{1}{\sigma}} \\
I & =S, U \text { and } i=s, u \\
\frac{\frac{\partial Y}{\partial S}}{\frac{\partial Y}{\partial U}} & =\left(\frac{a_{s}}{a_{u}}\right)^{\frac{\sigma-1}{\sigma}}\left(\frac{U}{S}\right)^{\frac{1}{\sigma}}
\end{aligned}
$$

Assuming perfect competition in the output and labor market, that is equating the marginal product of skilled and unskilled workers to their respective wages, denoted $w_{s}$ and $w_{u}$ the expression of the $(\log )$ relative skill premium, $\ln \frac{w_{s}}{w_{u}}=\omega_{s u}$ reads as:

$$
\omega_{s u}=\frac{\sigma-1}{\sigma} \ln \frac{a_{s}}{a_{u}}-\frac{1}{\sigma} \ln \frac{\bar{S}}{\bar{U}}
$$


Equation 13 is used by Katz and Murphy (1992) to link developments in the skill premium with developments in the relative supply of skilled and unskilled workers. Katz and Murphy argue that changes in the skill premium in the US are consistently explained by steady demand shifts. The shifts in the relative demand for skilled workers are further assumed to come about because of skillbiased technical change. In their model, skill-biased technical change only enters the equation via upward shifts in the relative productivity of skilled workers $\ln a_{s u}$.

$$
\begin{aligned}
\omega_{s u, t}= & \frac{\sigma-1}{\sigma} \ln a_{s u, t}-\frac{1}{\sigma} \ln \frac{\bar{S}_{t}}{\bar{U}_{t}} \\
& \text { with } \\
\ln a_{s u, t}= & \ln a_{s u}+\delta t
\end{aligned}
$$

Hence, the type of technical change Katz and Murphy consider is restricted to proportional shifts in the distribution of relative productivity of skilled (college graduates) and unskilled (high-school graduates) workers. We argue that, in addition, technical changes may twist the distribution of relative productivity of skilled workers.

Proposition $2 A$ decrease in the elasticity of substitution between skilled and unskilled workers $\sigma$, increases (decreases) wage dispersion if and only if the supply of skilled workers measured in efficiency units is smaller (larger) than the supply 
of unskilled workers. ${ }^{14}$

Proof. We derive equation 14 with respect to $\sigma$. We have:

$$
\begin{aligned}
\frac{\partial \omega_{s u, t}}{\partial \sigma} & =\sigma^{-2} \ln \frac{a_{s, t} \bar{S}_{t}}{a_{u, t} \bar{U}_{t}}<0 \\
& \Leftrightarrow a_{s, t} \bar{S}_{t}<a_{u, t} \bar{U}_{t}
\end{aligned}
$$

This suggests that wage inequality could either increase or decrease in response to skill-biased technical change as depicted in proposition 2 depending on whether the supply of skilled workers measured in efficiency units is larger or smaller than the supply of unskilled workers.

Three sources of income per capita growth

To single out the various sources of income per capita growth, we normalize the CES production function at time 0 , where time 0 corresponds to the timing of the structural break (see de La Granville (1989) and Klump and Preissler (2000)).

\footnotetext{
${ }^{14}$ The relative supply of college graduates in the US grew steadily from 0.21 in 1963 to 0.32 in 1974, 0.45 in 1991 and 0.58 in 2002. Therefore, for the supply of skilled workers measured in efficiency units to be larger than the supply of unskilled workers, the efficiency of skilled workers must be $3.8=0.79 / 0.21$ times larger than the efficiency of unskilled workers in 1963, 2.1 times larger in 1974, 1.2 times larger in 1991 and only 0.7 times larger in 2002.
} 


$$
Y_{t}=Y_{0}\left(\left(1-b_{t}\right)\left(\frac{U_{t}}{U_{0}}\right)^{\frac{\sigma-1}{\sigma}}+b_{t}\left(\frac{S_{t}}{S_{0}}\right)^{\frac{\sigma-1}{\sigma}}\right)^{\frac{\sigma}{\sigma-1}}
$$

with $Y_{0}$ the output at time $0, S_{0}$ and $U_{0}$ the supply of skilled and unskilled workers at time 0 and $b_{t}$ a parameter indicating the relative efficiency of skilled to unskilled workers at time $t$.

The long run labor productivity, denoted $y_{t}=Y_{t} /\left(S_{t}+U_{t}\right)$, can be written as a function of the proportion of skilled workers in the firm, denoted $p_{t}\left(p_{t}=\frac{S_{t}}{U_{t}+S_{t}}\right)$.

$$
y_{t}=g_{\sigma}\left(p_{t}\right)=Y_{0}\left(\left(1-b_{t}\right) U_{0}^{\frac{1-\sigma}{\sigma}}\left(1-p_{t}\right)^{\frac{\sigma-1}{\sigma}}+b_{t} S_{0}^{\frac{1-\sigma}{\sigma}} p_{t}^{\frac{\sigma-1}{\sigma}}\right)^{\frac{\sigma}{\sigma-1}}
$$

Writing $a_{u, t}=Y_{0}\left(1-b_{t}\right)^{\frac{\sigma}{\sigma-1}} U_{0}^{-1}$ and $a_{s, t}=Y_{0} b_{t}^{\frac{\sigma}{\sigma-1}} S_{0}^{-1}$ or $b_{t}=\frac{\left(\frac{a_{s, t}}{a_{u, t}} \frac{S_{0}}{U_{0}}\right)^{\frac{\sigma-1}{\sigma}}}{1+\left(\frac{a_{s, t}}{a_{u, t}} \frac{S_{0}}{U_{0}}\right)^{\frac{\sigma-1}{\sigma}}}$, the indirect production function derived from the assignment of tasks to workers reads as a normalized CES production function and the derived labor productivity function reads as the $g$ function:

$$
\begin{aligned}
& Y_{t}=\left(\left(a_{u, t} U_{t}\right)^{\frac{\sigma-1}{\sigma}}+\left(a_{s, t} S_{t}\right)^{\frac{\sigma-1}{\sigma}}\right)^{\frac{\sigma}{\sigma-1}} \\
& y_{t}=g_{\sigma}\left(p_{t}\right)=\left(\left(a_{u, t}\left(1-p_{t}\right)\right)^{\frac{\sigma-1}{\sigma}}+\left(a_{s, t} p_{t}\right)^{\frac{\sigma-1}{\sigma}}\right)^{\frac{\sigma}{\sigma-1}}
\end{aligned}
$$

Labor productivity growth is: 


$$
\frac{\dot{y}}{y}=\frac{1}{g_{\sigma}}\left(\frac{\partial g_{\sigma}}{\partial \sigma} \frac{d \sigma}{d t}+\frac{\partial g_{\sigma}}{\partial p} \frac{d p}{d t}+\frac{\partial g_{\sigma}}{\partial b} \frac{d b}{d t}\right)
$$

Equation 20 indicates the three sources of labor productivity growth:

1. twists, initiated by changes in the elasticity of substitution $\frac{\partial g_{\sigma}}{\partial \sigma}$,

2. supply, initiated by changes in the skill employment share $\frac{\partial g_{\sigma}}{\partial p}$ and,

3. shifts, initiated by changes in the relative efficiency units of skilled labor $\frac{\partial g_{\sigma}}{\partial b}$.

Some authors reject the SBTC explanation of wage inequality because technical improvements should have been associated with a faster growth whereas in the past 25 years, the US income per capita grew slower ${ }^{15}$ (see Acemoglu (2002)). In this paper, we show that the exogenous technical changes described in propositions 1 and 2 actually may contribute to a slowdown or a speedup in the growth of income per capita depending on whether these technical changes decrease or increase the elasticity of substitution (twists). To show this, we prove the following proposition:

\footnotetext{
${ }^{15}$ The US TFP growth decreases from 3.4 percent per year from 1960 to the early 70 s to 1.3 percent per year thereafter until the mid-90s (see Kozicki (1997)). The figures published by the Bureau of Labor Statistics regarding the growth in labor productivity are: 3.3\% per year between 1948 and 1973, 1.3\% between 1973 and 1979, 1.6\% between 1979 and 1990 and 1.5\% between 1990 and 1995 .
} 
Proposition 3 If the economy is described by a CES production function and the elasticity of substitution between skilled and unskilled workers $\sigma$ decreases through time, then the growth of labor productivity slows down.

Proof. We first rearrange equation 19 as follows: ${ }^{16}$

$$
y_{t}=p_{t} f_{\sigma}\left(p_{t}\right)=p_{t} \frac{Y_{0}}{S_{0}}\left(\left(1-b_{t}\right)\left(\frac{1-p_{t}}{1-p_{0}} \frac{p_{0}}{p_{t}}\right)^{\frac{\sigma-1}{\sigma}}+b_{t}\right)^{\frac{\sigma}{\sigma-1}}
$$

Hence, to prove that $\frac{\partial g_{\sigma}}{\partial \sigma}>0$ for any $p_{t} \neq p_{0}$ it is enough to prove that $\frac{\partial f_{\sigma}}{\partial \sigma}>0$ for any $p_{t} \neq p_{0}$. Deriving $f_{\sigma}$ with respect to $\sigma$ and rearranging we have:

$$
\frac{\partial f_{\sigma}}{\partial \sigma}=\frac{y_{t}}{(\sigma-1)^{2}}\left[\begin{array}{c}
\frac{\sigma-1}{\sigma} \frac{\left(1-b_{t}\right) \chi_{t}^{\frac{\sigma-1}{\sigma}} \ln \chi_{t}}{\left(1-b_{t}\right) \chi_{t}^{\frac{\sigma-1}{\sigma}}+b_{t}} \\
-\ln \left[\left(1-b_{t}\right) \chi_{t}^{\frac{\sigma-1}{\sigma}}+b_{t}\right]
\end{array}\right]
$$

where $\chi_{t}=\frac{1-p_{t}}{1-p_{0}} \frac{p_{0}}{p_{t}}$.

Since $\sigma>1$, once rearranging we have that $\frac{\partial f_{\sigma}}{\partial \sigma} \geq 0$ if and only if:

$$
\left(1-b_{t}\right) \chi_{t}^{\frac{\sigma-1}{\sigma}} \ln \chi_{t}^{\frac{\sigma-1}{\sigma}}-\left(\left(1-b_{t}\right) \chi_{t}^{\frac{\sigma-1}{\sigma}}+b_{t}\right) \ln \left(\left(1-b_{t}\right) \chi_{t}^{\frac{\sigma-1}{\sigma}}+b_{t}\right) \geq 0
$$

${ }^{16}$ Note that Klump and de La Granville (2000) use the functional form:

$$
\frac{Y_{t}}{S_{t}}=f_{\sigma}\left(k_{t}\right)=\frac{Y_{0}}{S_{0}}\left(\left(1-b_{t}\right)\left(\frac{k_{t}}{k_{0}}\right)^{\frac{\sigma-1}{\sigma}}+b_{t}\right)^{\frac{\sigma}{\sigma-1}}
$$

where $k_{t}=\frac{U_{t}}{S_{t}}=\frac{1-p_{t}}{p_{t}}$

and proved that $\frac{\partial f_{\sigma}\left(k_{t}\right)}{\partial \sigma}>0$. 
We define the function $k\left(m_{t}\right)$ as follows:

$$
k\left(m_{t}\right)=\left(1-b_{t}\right) m_{t} \ln m_{t}-\left(\left(1-b_{t}\right) m_{t}+b_{t}\right) \ln \left(\left(1-b_{t}\right) m_{t}+b_{t}\right)
$$

where $m_{t}=\chi_{t}^{\frac{\sigma-1}{\sigma}}$.

We need to prove that the function $k$ is greater than 0 for all $b_{t} \in(0,1)$ and $m_{t}>0$. We first note that $k(1)=0$ for all $b_{t},{ }^{17} \lim _{m_{t} \rightarrow 0} k\left(m_{t}\right)=-b_{t} \ln b_{t}>0$ for all $b_{t} \in(0,1)$. Then we derive $k$ and obtain:

$$
k^{\prime}\left(m_{t}\right)=\left(1-b_{t}\right) \ln \left(\frac{m_{t}}{\left(1-b_{t}\right) m_{t}+b_{t}}\right)
$$

From Equation (25) we see that $k^{\prime}<0$ for all $b_{t}$ on $0<m_{t}<1, k^{\prime}>0$ for all $b_{t}$ and $1<m_{t}$ and $k^{\prime}=0$ for $m_{t}=1$. Therefore, the function $k\left(m_{t}\right)$ is monotonic strictly decreasing on $m_{t} \in(0,1]$ and monotonic strictly increasing on $m_{t} \in[1, \infty)$. From this we can conclude that the function $k\left(m_{t}\right)$ is strictly greater than 0 for all $b_{t}$ and all $m_{t}=\chi_{t}^{\frac{\sigma-1}{\sigma}}=\left(\frac{1-p_{t}}{1-p_{0}} \frac{p_{0}}{p_{t}}\right)^{\frac{\sigma-1}{\sigma}} \neq 1$ and equal to 0 for $m_{t}=1$ (conform $\left.p_{t}=p_{0}\right)$. This implies that the inequality represented in equation (23) is satisfied and therefore that $\frac{\partial f_{\sigma}}{\partial \sigma}>0$ and $\frac{\partial g_{\sigma}}{\partial \sigma}>0$ for all $p_{t} \neq p_{0}$ and equal to zero for $p_{t}=p_{0}$.

Since $\frac{\partial g_{\sigma}}{\partial \sigma}>0$ for all $p_{t} \neq p_{0}$, the growth in labor productivity slows down as the elasticity of substitution decreases through time.

\footnotetext{
${ }^{17}$ Note that $m_{t}=1$ if and only if $p_{t}=p_{0}$
} 
The following proposition indicates that labor productivity growth is partially driven by the growth of the skill employment share (supply).

Proposition 4 If the economy is described by a CES production function, an increase in the employment share of skilled labor at time $t$ will increase labor productivity growth if and only if the skill premium is strictly positive, $\omega_{s u, t}>0$.

Proof. Deriving equation 19 with respect to $p_{t}$ yields:

$$
\frac{\partial g_{\sigma}}{\partial p_{t}}=g_{\sigma}^{\frac{1}{\sigma}}\left[\left(a_{s, t}\right)^{\frac{\sigma-1}{\sigma}} p_{t}^{-1 / \sigma}-\left(a_{u, t}\right)^{\frac{\sigma-1}{\sigma}}\left(1-p_{t}\right)^{-1 / \sigma}\right]
$$

Hence, $\frac{\partial g_{\sigma}}{\partial p_{t}}>0 \Leftrightarrow \frac{p_{t}}{1-p_{t}}=\frac{S_{t}}{U_{t}}<\left(\frac{a_{s, t}}{a_{u, t}}\right)^{\sigma-1}$.

Note that since $\sigma>0$, this condition can be written as: $\left(\frac{S_{t}}{U_{t}}\right)^{1 / \sigma}<\left(\frac{a_{s, t}}{a_{u, t}}\right)^{\frac{\sigma-1}{\sigma}} \Leftrightarrow$ $\frac{1}{\sigma} \ln \frac{S_{t}}{U_{t}}<\frac{\sigma-1}{\sigma} \ln \frac{a_{s, t}}{a_{u, t}}$. Using equation 13 we conclude that $\frac{\partial g_{\sigma}}{\partial p_{t}}>0 \Leftrightarrow \omega_{s u, t}>0$.

Finally, the following proposition indicates that the growth of labor productivity is driven by changes in the relative efficiency parameter of skilled labor (shifts).

Proposition 5 If the economy is described by a CES production function, an increase in the relative efficiency of skilled labor, i.e. $b_{t}$, at time $t$ will increase labor productivity growth if and only if the relative employment of skilled workers at time $t$ is strictly greater than initial relative employment at time 0 , i.e. $\frac{S_{0}}{U_{0}}$.

Proof. Deriving equation 16 with respect to $b_{t}$ yields: 


$$
\frac{\partial g_{\sigma}}{\partial b_{t}}=\frac{\sigma}{\sigma-1} Y_{0}^{\frac{\sigma-1}{\sigma}} g_{\sigma}^{\frac{1}{\sigma}}\left[S_{0}^{\frac{1-\sigma}{\sigma}} p_{t}^{\frac{\sigma-1}{\sigma}}-U_{0}^{\frac{1-\sigma}{\sigma}}\left(1-p_{t}\right)^{\frac{\sigma-1}{\sigma}}\right]
$$

Hence, $\frac{\partial g_{\sigma}}{\partial b_{t}}>0 \Leftrightarrow \frac{p_{t}}{1-p_{t}}=\frac{S_{t}}{U_{t}}>\frac{S_{0}}{U_{0}}$.

\section{Empirical analysis}

Data

Our data consist of annual US time-series of labor between 1963 and 2002. The data for the period 1963-1992 are made available by Krusell et al. (2000). ${ }^{18}$

We use the CPS March supplements files for the years 1993-2003 and derive changes in the relative supply of skills and the skill premium between 1992 and 2002. We use the procedure proposed by Katz and Autor (2000) and described in Acemoglu (2002). The relative supply of skills is calculated from a sample that includes all workers between the ages of 18 and 65 and defined by the ratio of college equivalents to non-college equivalents using weeks worked as weights. College equivalents equals the number of college graduates (at least 16 years of schooling) to which we add half of the workers with some college (strictly more than 12 years of schooling and less than 15 years of schooling). The non-college equivalents equal high-school dropouts plus high-school graduates to which we add the other half of workers with some college.

\footnotetext{
${ }^{18}$ The data can be obtained from Violante's website, http://www.ucl.ac.uk. For more details on the sources and construction of the data see Krusell et al. (2000).
} 
The college premium is the coefficient for workers with at least a college degree in a log weekly wage regression. The regression includes dummies for other educational categories, experience and its square, a nonwhite dummy, a female dummy and interactions between the female dummy and the nonwhite dummy and the experience controls. The sample includes full-time full-year workers between the ages of 18 and 65 .

The series from 1963 to 1992 are then extended to 2002 by applying the calculated changes on the last year observation of the Krusell et al. series.

The relative supply of skilled workers to unskilled workers increased more than twofold over the period considered. The skill premium increases through the $60 \mathrm{~s}$, then declines through the 70s to rise sharply after 1980 (see figure 2).

$<$ insert figure $2>$

Testing for shifts and twists in relative productivity of skilled labor

Consider the class of skill-biased technical change models described by Katz and Murphy (1992).

KM Model

$$
\begin{aligned}
\omega_{s u, t} & =\gamma_{0}+\gamma_{1} \ln \frac{S_{t}}{U_{t}}+\gamma_{2} t+\xi \\
& =-\frac{1}{\sigma} \ln \frac{S_{t}}{U_{t}}+\frac{\sigma-1}{\sigma} \delta t+\frac{\sigma-1}{\sigma} \ln a_{s u}+\xi_{t}
\end{aligned}
$$


where $\ln a_{s u}$, the relative efficiency parameter in 1963, is a constant and $\xi$ an error term satisfying the usual properties, IID.

In these models, new technologies increase the relative productivity of skilled workers proportionally in all tasks. The elasticity of substitution between labor types, given by $\sigma=-1 / \gamma_{1}$, is assumed constant over time. The demand shifts are captured by a linear time trend, i.e. $\gamma_{2}=\frac{\sigma-1}{\sigma} \delta$ indicating the yearly growth rate in the relative demand for skills. The estimation results of the KM Model, reported in the first column of Table 1, are consistent with findings in the literature. ${ }^{19}$ The elasticity of substitution between types of labor is 1.56 and the demand for skills shifts steadily at a yearly rate of 2.2 percent. The result indicates that technical change has increased the relative productivity of skilled workers in all tasks. However, in the KM Model, demand for skills shifts steadily over time whereas some authors (see Acemoglu (2002)) argued in favor of an acceleration of SBTC during the 80s. We extent the model to capture a possible acceleration in SBTC during the 80s (e.g. Acemoglu (2002)) by adding time squared, cubed and fourth time order in the regression. As reported in Table 1 , the third and fourth time order are significant at $10 \%$. As previously found

\footnotetext{
${ }^{19}$ Note that the relative supply and skill-premium series are nonstationary, i.e. I(1). The Augmented Dickey-Fuller statistics, with drift, for the respective series are -1.09 and -1.1 and not significant. However, the series are cointegrated, $A D F-$ statistic $=-3.89$ significant at $1 \%$, such that the OLS estimates presented in table 1 are consistent. Moreover, the t-statistics of the coefficients estimated by Error Correction Regression are all significant which confirms that the coefficients of the KM model reflect a structural (and not spurious) long run relationship.
} 
by Acemoglu (2002) with data on the period 1939-1996, we find (weak) evidence for an acceleration in the SBTC during the period 1963-2002. As illustrated in Figure 3, three periods can be distinguished. First we observe a deceleration in SBTC until the mid 70 s, the rate of demand shifts drops from $2.5 \%$ per year in 1963 to $1.8 \%$ in the mid 70s, then an acceleration in SBTC through the 80s, the rate of demand shifts increases to $2.3 \%$ through the $80 \mathrm{~s}$ and a deceleration thereafter.

$<$ Insert Table 1>

According to Proposition 1, technical change may increase (respectively decrease) the relative productivity of skilled labor relatively more in cognitive tasks and decrease (increase) the relative productivity of unskilled workers relatively more in manual tasks. These changes in the distribution of comparative advantage result in changes in the elasticity of substitution.

We therefore investigate empirically the stability of not only the efficiency parameters but also the elasticity of substitution over time. To this aim we estimate equation 26 using rolling regression techniques with a window of 15 years through the span 1963-2002. The results of these rolling regressions are illustrated in Figure 4. The last year of each window is reported on the horizontal axis whereas the magnitude of the respective estimates of $\sigma$ and time trend are reported on the vertical axis of panel a and b respectively. For instance, for 1980, parameters of interest have been estimated using the span 1966-1980. Clearly $\sigma$ is not constant nor is the trend parameter. Note that the trend parameter seems 
to be decreasing between $64-78$ and $67-81$ at the same pace as between $75-89$ and 88-02. This suggests that $\gamma_{2}=\alpha_{1}+\alpha_{2} t$ with $\alpha_{2}<0$. We therefore augment equation 26 with time squared and run the rolling regression on the "augmented" equation 26. The results are illustrated in Figure 5. The first panel indicates that $\sigma$ is high before $67-81$, drops between $68-82$ and $76-90$ and comes back to its initial level after $77-91 .^{20}$ The time trend parameter seems to be relatively low until 75-89 and high thereafter. The time squared parameter is first low until 68-82, then high until 76-90 and low again thereafter. To summarize, Figure 5 clearly indicates that the parameters of the augmented KM Model are unstable and know two states, high and low. There are actually three distinct regimes: the first regime has a high $\sigma$ and low time trend and time squared parameters, the second regime has a low $\sigma$, a low time trend parameter and high time squared parameter and finally the third regime has a high $\sigma$, a high time trend parameter and a low time squared parameter.

To account for these patterns, we therefore estimate the Shifts and Twists Model (ST Model from now on) defined by equation (28) allowing for three regimes, two states (high and low) and two break dates. Since the break dates of the parameters are a priori unknown, we use the Quandt-statistic that corre-

\footnotetext{
${ }^{20}$ Note that the magnitude of the various estimates is relatively large compared to the magnitude of the estimates obtained either with the KM Model or the Shifts and Twists Model. This is due to a relatively high multicolinearity between relative supply and time within the various windows. Estimating the model at given magnitude of the elasticity of substitution (respectively time trend) within each window gives estimates for the time trend (elasticity of substitution) of similar magnitude as the estimates of the ST model for the corresponding period.
} 
sponds to the largest Chow statistic, Sup - Chow, measured on the period under scrutiny. We run the Chow statistic for the stability of the augmented KM Model for all years in the sample and find that the Quandt-statistic is equal to 12.33, significant at 1\% and the corresponding break dates are 1977 and 1991.

\section{ST Model}

$$
\begin{aligned}
\omega_{s u, t}= & \gamma_{0}+\gamma_{1} \ln \frac{S_{t}}{U_{t}}+\gamma_{2} t+\gamma_{3} t^{2}+ \\
& \left(\gamma_{1 T_{77-91}} \ln \frac{S_{t}}{U_{t}}+\gamma_{3 T_{77-91}} t^{2}\right) D_{T_{77-91}} \\
& \gamma_{2 T_{91-02}} \times t \times D_{T_{91-02}}+\varepsilon_{t}
\end{aligned}
$$

where $D_{T_{77-91}}=\left(\begin{array}{c}1 \text { if } 1977 \leq t<1990 \\ 0 \text { if } t<1977 \text { or } t \geq 1991\end{array}\right)$ and $D_{T_{91-02}}=\left(\begin{array}{l}1 \text { if } t \geq 1990 \\ 0 \text { if } t<1991\end{array}\right)$

\section{$<$ Insert Table $2>$}

The results are reported in Table 2. The fit of the ST Model is better than the KM Model with acceleration of SBTC as indicated by the adjusted $R^{2}$ (see Table 2 below). ${ }^{21}$ In the ST Model there are two break dates in the long run relationship between skill premium and relative supply that define three regimes and two states. In the first regime covering the period 1963-1977, the relative demand for

\footnotetext{
${ }^{21}$ The long run relationship depicted in the ST Model is stationary, ADF - statistic $\left(\widehat{\varepsilon}_{t}\right)=$ -7.024 significant at $1 \%$, such that the OLS estimates presented in table 2 are consistent. Moreover, $\gamma_{1}, \gamma_{1 T_{77-91}}, \gamma_{2}$ and $\gamma_{3 T_{91-02}}$ estimated by Error Correction Regression are significant which confirms that the coefficients of the ST Model reflect a structural (and not spurious) long run relationship.
} 
skills shifts at an annual rate of $1.7 \%$ with a yearly deceleration of $0.099 \%$. In the second regime covering the period 1977 to 1990, the relative demand for skills still shifts at an annual rate of $1.7 \%$ but with a yearly acceleration of $0.227 \%$. After 1991, the relative demand for skills shifts at an annual rate of $2.0 \%$ with a yearly deceleration of $0.099 \%$. Moreover, in the periods $1963-1976$ and $1991-2002$ the elasticity of substitution between skill types is relatively large and equal to 2.22. However, between 1977 and 1990, the elasticity of substitution is significantly lower and equal to $1.50 .^{22}$

The results provide strong empirical support for the relevance of Proposition 1. The technical changes observed between 1963 and 2002 have altered the distribution of comparative advantage among skilled and unskilled workers differently in the various tasks. The decrease in the elasticity of substitution at the end of the 70s suggest that skilled workers have become relatively more productive in cognitive tasks whereas unskilled workers have become relatively more productive in manual tasks. In contrast, the increase of the elasticity of substitution indicates a twist in the opposite direction.

\section{Sources of skill premium growth}

As indicated by proposition 2 , technical change affecting the ease to substitute between labor types may affect wage dispersion. To investigate empirical

\footnotetext{
${ }^{22}$ This result seems to be consistent with other empirical results. Acemoglu (2002), using a time-series from 1939 to 1996, finds an elasticity of 1.9, while Katz and Murphy (1992) estimate $\sigma=1.4$ for the period 1963-1987.
} 
evidence for proposition 2, we use the estimates of the ST Model to derive expost predictions of the skill premium. The average annual growth of these ex-post predictions of the skill premium is then decomposed into:

1. the contribution of shifts, i.e. the average annual growth rate of

$$
\left(\widehat{\gamma}_{2}+\widehat{\gamma}_{2, T_{91-02}} D_{T_{91-02}}\right) t+\left(\widehat{\gamma}_{3}+\widehat{\gamma}_{3, T_{77-91}} D_{T_{77-91}}\right) t^{2}
$$

2. the contribution of supply at constant elasticity of substitution over time, i.e. the average annual growth rate of $\widehat{\gamma}_{1} \ln \frac{S}{U}$ and,

3. the contribution of twists, i.e. the average annual growth rate of the expost predictions of equation 28 , i.e. $\widehat{\omega}_{s u, t}$, less the contribution of supply and shifts.

Also the contribution of the errors of the model are accounted for as the observed average annual growth less the ex-post predictions average annual growth. This decomposition is reported in Table 3 together with the decomposition corresponding to the KM Model. The decrease in the elasticity of substitution in 1977 has contributed to a narrowing in wage dispersion between 1977 and 1991. However, this narrowing has been offset by the shifts contribution of a magnitude twice as large in that period. Remarkably enough, shifts have had almost no effects on wage dispersion after 1991 whereas twists have contributed to a large wage widening between 1991 and 2002 only partly offset by the increasing skills supply. These empirical figures stem for the importance of twists, that is 
changes in the elasticity of substitution, in explaining patterns of skill premium over time.

Sources of labor productivity growth

Proposition 3 indicates that technical change increasing the ease to substitute between labor types will lead to an acceleration in labor productivity growth whereas labor productivity slows down when technical change decreases the elasticity of substitution. We therefore investigate empirical evidence for proposition 3 and use the estimates of the ST Model to derive ex-post predictions of average labor productivity growth. The predictions of labor productivity growth are derived using equation 20 where $p_{t}$ is the employment share of skilled labor and

$$
\begin{aligned}
& \widehat{a}_{u, t}=Y_{63}\left(1-\widehat{b}_{t}\right)^{\frac{\hat{\sigma}}{\hat{\sigma}-1}} \text { and } \widehat{a}_{s, t}=Y_{63} \widehat{b}_{t}^{\frac{\hat{\sigma}}{\sigma-1}} \text {, } \\
& \widehat{b}_{t}=\frac{\exp \left(\widehat{\gamma}_{0}+\left(\widehat{\gamma}_{2}+\widehat{\gamma}_{2, T_{91-02}} D_{T_{91-02}}\right) t+\left(\widehat{\gamma}_{3}+\widehat{\gamma}_{3, T_{77-91}} D_{T_{77-91}}\right) t^{2}\right)}{1+\exp \left(\widehat{\gamma}_{0}+\left(\widehat{\gamma}_{2}+\widehat{\gamma}_{2, T_{91-02}} D_{T_{91-02}}\right) t+\left(\widehat{\gamma}_{3}+\widehat{\gamma}_{3, T_{77-91}} D_{T_{77-91}}\right) t^{2}\right)}, \\
& \text { and } \widehat{\sigma}=-\frac{1}{\widehat{\gamma}_{1}+\widehat{\gamma}_{1, T_{77-91}} D_{T_{77-91}}} \text {. }
\end{aligned}
$$

The contribution of supply, shifts and twists to average labor productivity growth are reported in Table 3. The decrease of $\sigma$ after 1977 has contributed to a slowdown of 0.05 percentage points in labor productivity growth between 1977 and 1990 whereas the increase of $\sigma$ after 1990 has contributed to an acceleration of labor productivity growth of 0.11 percentage points after 1991 . The decrease in the elasticity of substitution that occurs in 1977 has contributed to a slowdown in labor productivity throughout the 80 s whereas the increase in the elasticity of substitution in the early 90s has contributed to speed up labor productivity 
throughout the $90 \mathrm{~s}$.

Note that the employment share of skilled workers increased between 1963 and 2002 and therefore contributed to labor productivity growth in the first and third regimes since as indicated by proposition 4 the skill premium was positive in these regimes (see Figure 2), $\omega_{s u, t}>0$. However, in the second regime, the skill premium was negative between 1978 and 1981 so that the increase in the employment share of skilled workers has contributed to a slowdown in labor productivity growth.

Moreover, as indicated by proposition 5, the increase in the relative efficiency of skilled workers, i.e.

$$
\frac{d \widehat{b}_{t}}{d t}=\widehat{\gamma}_{0}+\left(\widehat{\gamma}_{2}+\widehat{\gamma}_{2, T_{91-02}} D_{T_{91-02}}\right) t+\left(\widehat{\gamma}_{3}+\widehat{\gamma}_{3, T_{77-91}} D_{T_{77-91}}\right) t^{2}>0 \text { for all } t>1
$$
has contributed to labor productivity growth between 1963-2002 since $\frac{p_{t}}{1-p_{t}}=$ $\frac{S_{t}}{U_{t}}>\frac{S_{0}}{U_{0}}$ and $d b_{t}>0$ for all $t .^{23}$

Finally, we derived a contrafactual series of labor productivity with constant elasticity of 2.2 through 1963-2002. Comparing this contrafactual series with the series with changes in the elasticity of substitution reveals the contribution of the change in the elasticity of substitution in labor productivity growth over time. The predictions of labor productivity in both models are derived using equation 19:

\footnotetext{
${ }^{23}$ This result does not depend on the initial relative employment since skilled labor has increased throughout the span 1963-2002.
} 


$$
y_{t}=g_{\sigma}\left(p_{t}\right)=\left(\left(a_{u, t}\left(1-p_{t}\right)\right)^{\frac{\sigma-1}{\sigma}}+\left(a_{s, t} p_{t}\right)^{\frac{\sigma-1}{\sigma}}\right)^{\frac{\sigma}{\sigma-1}}
$$

where $p_{t}$ is employment share of skilled labor and $\widehat{\sigma}=-\frac{1}{\widehat{\gamma}_{1}+\widehat{\gamma}_{1, T_{77-91}} D_{T_{77-91}}}$ for the series with change in the elasticity of substitution and $\widehat{\sigma}=-\frac{1}{\hat{\gamma}_{1}}$ for the series without change in $\sigma$.

The growth rate of labor productivity predicted by the model with a decrease of $\sigma$ after 1977 and an increase after 1991 lies in average 0.10 percentage points below that of the model with constant $\sigma$ in the period 1977-1990 and 0.12 percentage above after 1991.

Acemoglu (2002) argues that the main difficulty with an acceleration in the gross SBTC, through a time trend or through the capital-skill complementarity (see Krusell et al. (2000) for instance) is that: "It is difficult to imagine how a new and radically more profitable technology will first lead to 25 years of substantially slower growth" (see Acemoglu (2002), p. 34). The skill-biased technological changes Acemoglu refers to are associated with shifts in the productivity of skilled compared to unskilled workers in favor of the skilled. We argued that technological changes observed in the last decades have not only shifted but also twisted the relative productivity of skilled to unskilled workers. The twists in the distribution of relative productivity are reflected by changes in the magnitude of the elasticity of substitution between both labor types. In this paper, we showed that the decrease in the elasticity of substitution between skill types of labor 
at the end of the 70s has contributed to the slowdown in output growth which therefore is reconcilable with an acceleration in SBTC. Moreover, the increase in the elasticity of substitution after 1991 coincides with an acceleration in labor productivity during the 90s. ${ }^{24}$ Hansen (2001) shows that US labor productivity in the manufacturing sector series breaks in 1982 (weak evidence) and in 1994.

\section{Conclusion}

This paper departs from the standard literature on skill-biased technical change (e.g. Katz and Murphy (1992)) by releasing the implicit assumption that the relative productivity of skilled workers increased proportionally in every task. In the theoretical model we take a closer look at the possible effects of skill-biased technical change in the labor market, by analyzing how skill-biased technical change may affect the productivity of skilled workers relative to unskilled workers in a continuum of tasks. We show that the assignment model developed by Rosen (1978), not only offers a microfoundation for the CES production function, the workhorse model in the SBTC and growth literature, but also reveals a relationship between the elasticity of substitution across workers types and the slope of their productivity schedule across tasks. In this model, skill-biased technical change may lead to shifts and twists in the productivity schedule of skilled versus unskilled workers. Shifts correspond to increases in the relative

\footnotetext{
${ }^{24}$ It is widely recognized that US labor productivity slows down in the mid 70 s and speeds up in the second half of the 90s.
} 
efficiency parameters that are commonly associated with skill-biased technical change. Twists reflect changes in the elasticity of substitution between skilled and unskilled workers that have been absent in the skill-biased technical change literature.

Empirical investigation stems for the non stability of the parameters of an augmented Katz and Murphy (1992) model. We show strong empirical evidence that the elasticity of substitution between skilled and unskilled labor has changed over time. This variability of the elasticity of substitution over time is of importance as it (twist) explains a significant part of the rise in the skill premium after 1977 but also part of the productivity slowdown observed in the 70s and 80s and acceleration in the $90 \mathrm{~s}$ as the magnitude of the elasticity of substitution between inputs is directly linked to the growth rate of income per capita as already recognized in the literature on economic growth.

\section{References}

Acemoglu, D. (2002): "Technical Change, Inequality and the Labor Market," Journal of Economic Literature, 40(1), 7-72.

Autor, D., L. Katz, And A. Krueger (1998): "Computing Inequality: Have Computers Changed the Labor Market?," Quarterly Journal of Economics, 113(4), 1169-213. 
Autor, D., F. Levy, and R. Murnane (2003): "The Skill Content of Recent Technological Change: An Empirical Exploration," Quarterly Journal of Economics, 118(4).

BARRAS, R. (1990): "Interactive Innovation in Financial and Business Services: The Vanguard of the Service Revolution," Research Policy, 19, 215-37.

Berman, E., J. Bound, And Z. Griliches (1994): "Changes in the Demand for Skilled Labor Within US Manufacturing: Evidence from Annual Survey of Manufactures," Quarterly Journal of Economics, 109(1), 367-97.

Berman, E., J. Bound, And S. Machin (1998): "Implications of Skill-Biased Technological Change: International Evidence," Quarterly Journal of Economics, 113(4), 1245-79.

Bound, J., And G. Johnson (1992): "Changes in the Structure of Wages During the 1980's: An Evaluation of Alternative Explanations," American Economic Review, 82(3), 371-92.

Bresnahan, T. (1999): "Computerisation and Wage Dispersion: An Analytical Reinterpretation," Economic Journal, 109(456), 390-415.

Bresnahan, T., E. Brynjolfsson, and L. Hitt (2002): "Information Technology, Workplace Organization, and the Demand for Skilled Labor: FirmLevel Evidence," Quarterly Journal of Economics, 117(1), 339-76. 
Brynjolfsson, E., And L. Hitt (1995): "Information Technology as a Factor of Production: The Role of Differences Among Firms," Economics of Innovation and New Technology, 3(3-4), 183-99.

Card, D., And T. Lemieux (2001): "Can Falling Supply Explain the Rising Return to College for Younger Men? A Cohort-Based Analysis," Quarterly Journal of Economics, 116(2), 705-46.

Castro, R., And D. Coen-Pirani (2005): "Why Have Aggregate Skilled Hours Become So Cyclical Since the Mid1980's?," Working Paper.

Ciccone, A., And G. Peri (2005): "Long-Run Substitutability Between More and Less Educated Workers: Evidence from U.S. States 1950-1990," Review of Economics and Statistics, 87(4), forthcoming.

De La Grandville, O. (1989): "In Quest of the Slutsky Diamond," American Economic Review, 79(3), 468-81.

Ekeland, I., J. J. Heckman, and L. Nesheim (2004): "Identification and Estimation of Hedonic Models," Journal of Political Economy, 112(2), S60S109.

Fischer, S. (1988): "Symposium on the Slowdown in Productivity Growth," Journal of Economic Perspectives, 2(4), 3-8.

Greenwood, J., And M. Yorukoglu (1997): “1974," Carnegie-Rochester Conference Series on Public Policy, 46, 49-95. 
Griliches, Z. (1994): "Productivity, Research and Development and the Data Constraint," American Economic Review, 84(1), 1-23.

Hansen, B. (2001): "The New Econometrics of Structural Change: Dating Breaks in U.S. Labor Productivity," Journal of Economic Perspectives, 15(4), $117-28$.

Heckman, J. J., L. Lochner, and C. Taber (1998): "Explaining Rising Wage Inequality: Explorations with a Dynamic General Equilibrium Model of Labor Earnings with Heterogeneous Agents," Review of Economic Dynamics, $1,1-58$.

Hunter, L., A. Bernhardt, K. Hughes, and E. Skuratowicz (2001): "It's Not Just the ATMs: Technology, Firm Strategies, Jobs, and Earnings in Retail Banking," Industrial and Labor Relations Review, 54(2A), 402-24.

Jenker, P., And J. Jenker (1994): "Information Technology and Skills in Manufacturing and Construction," in Employment and Technical Change in Europe, ed. by K. Ducatel, chap. 4, pp. 56-77. Aldershot: Edward Elgar.

Katz, L., And D. Autor (2000): "Changes in the Wage Structure and Earnings Inequality," in Handbook of Labor Economics, ed. by O. Ashenfelter, and D. Card, chap. vol. III. Amsterdam: Elsevier.

Katz, L., And K. Murphy (1992): "Changes in Relative Wages, 1963-1987: Supply and Demand Factors," Quarterly Journal of Economics, 107(1), 35-78. 
Klump, R., and O. De La Grandville (2000): "Economic Growth and the Elasticity of Substitution: Two Theorems and Some Suggestions," American Economic Review, 90(1), 282-91.

Klump, R., And H. Preissler (2000): "CES Production Functions and Economic Growth," Scandinavian Journal of Economics, 102(1), 41-56.

KozICKI, S. (1997): "The Productivity Growth Slowdown: Diverging Trends in the Manufacturing and Service Sectors," Economic Review, 82(1), 31-46.

Krueger, A. (1993): "How Computers Have Changed the Wage Structure: Evidence from Microdata, 1984-1989.," Quarterly Journal of Economics, 110, $33-60$.

Krusell, P., L. Ohanian, J.-V. Ríos-Rull, and G. Violante (2000): "Capital-Skill Complementarity and Inequality: A Macroeconomic Analysis," Econometrica, 68(5), 1029-53.

LuCAs, R. (1977): "Hedonic Wage Equations and Psychic Wages in the Returns to Schooling," American Economic Review, 67(4), 549-58.

Nelson, R. R., And E. S. Phelps (1966): "Investment in Humans, Technology Diffusion and Economic Growth," American Economic Review, Papers and Proceedings, 56(2), 69-75.

Rosen, S. (1974): "Hedonic Prices and Implicit Markets: Product Differentiation in Pure Competition," Journal of Political Economy, 82, 34-55. 
Rosen, S. (1978): "Substitution and the Division of Labor," Economica, 45, $235-50$.

Solow, R. M. (1956): "A Contribution to the Theory of Economic Growth," Quarterly Journal of Economics, 70(1), 65-94.

Van Reenen, J., and E. Caroli (2001): "Skill-Biased Organisational Change? Evidence from British and French Establishments.," Quarterly Journal of Economics, 116(4), 1449-92.

Willis, R. (1986): "Wage Determinants: A Survey and Reinterpretation of Human Capital Earnings Functions," in Handbook of Labor Economics, ed. by O. Ashenfelter, and R. Layard, pp. 525-602. Amsterdam: North-Holland. 
Table 1: OLS regression of wage inequality.

\begin{tabular}{llllll}
\hline KM Model & & & \multicolumn{3}{c}{ Augmented KM Model } \\
& Coef. & Std_d & & Coef. & Std_d \\
$\ln \frac{S_{t}}{U_{t}}$ & $-0.639^{a}$ & 0.0472 & $\ln \frac{S_{t}}{U_{t}}$ & $-0.596^{a}$ & 0.0472 \\
$t$ & $0.022^{a}$ & 0.0016 & $t$ & $0.028^{a}$ & 0.0016 \\
Intercept & $0.014^{b}$ & 0.0068 & Intercept & 0.002 & 0.0053 \\
& & & $t^{2} \times 10$ & -0.011 & 0.0069 \\
& & & $t^{3} \times 100$ & $0.005^{c}$ & 0.0027 \\
& & & $t^{4} \times 10000$ & $-0.007^{c}$ & 0.0034 \\
$R_{a d j}^{2}$ & 0.934 & & & & \\
\hline \hline
\end{tabular}

${ }^{a} \operatorname{sig} 1 \%$

${ }^{b} \operatorname{sig} 5 \%$

${ }^{c} \operatorname{sig} 10 \%$ 
Table 2: OLS regression of wage inequality with 3 regimes and breaks in 1977 and 1991.

\begin{tabular}{|c|c|c|c|}
\hline $\begin{array}{l}\text { ST Model } \\
3 \text { Regimes } \\
\end{array}$ & Estimates & Coef. & \\
\hline $1963: 1976$ & $\begin{array}{l}\ln \frac{S_{t}}{U_{t}}\left(\widehat{\gamma}_{1}\right) \\
t\left(\widehat{\gamma}_{2}\right) \\
t^{2}(\times 1000)\left(\widehat{\gamma}_{3}\right) \\
\text { Intercept }\end{array}$ & $\begin{array}{r}-0.450 \\
0.017 \\
-0.099 \\
0.020\end{array}$ & $\begin{array}{r}\text { Elasticity, } \widehat{\sigma} \\
2.22 \\
\end{array}$ \\
\hline $1977: 1990$ & $\begin{array}{l}\ln \frac{S_{t}}{U_{t}}\left(\widehat{\gamma}_{1}+\widehat{\gamma}_{1 T_{77-91}}\right) \\
t\left(\widehat{\gamma}_{2}\right) \\
t^{2}(\times 1000)\left(\widehat{\gamma}_{3}+\widehat{\gamma}_{3 T_{77-91}}\right)\end{array}$ & $\begin{array}{r}-0.666 \\
0.017 \\
0.227\end{array}$ & $\begin{array}{r}\text { Elasticity, } \widehat{\sigma} \\
1.50 \\
\end{array}$ \\
\hline $1991: 2002$ & $\begin{array}{l}\ln \frac{S_{t}}{U_{t}}\left(\widehat{\gamma}_{1}\right) \\
t\left(\widehat{\gamma}_{2}+\widehat{\gamma}_{2 T_{91-02}}\right) \\
t^{2}(\times 1000)\left(\widehat{\gamma}_{3}\right)\end{array}$ & $\begin{array}{r}-0.450 \\
0.020 \\
-0.099\end{array}$ & $\begin{array}{r}\text { Elasticity, } \widehat{\sigma} \\
2.22\end{array}$ \\
\hline Parameters & $\begin{array}{l}\widehat{\gamma}_{1} \\
\widehat{\gamma}_{2} \\
\widehat{\gamma}_{3} \\
\text { Intercept } \\
\widehat{\gamma}_{1 T_{77-91}} \\
\widehat{\gamma}_{2 T_{91-02}} \\
\widehat{\gamma}_{3 T_{77-91}}\end{array}$ & $\begin{array}{c}\text { Coef } \\
-0.450^{a} \\
0.017^{a} \\
-0.099^{a} \\
0.020 \\
-0.216^{a} \\
0.003^{a} \\
0.327^{a}\end{array}$ & $\begin{array}{r}\text { Std_d } \\
0.0797 \\
0.0035 \\
0.0366 \\
0.0109 \\
0.0367 \\
0.0099 \\
0.0573\end{array}$ \\
\hline Statistic Tests & $\begin{array}{l}R_{\text {adj }}^{2} \\
\text { ADF - statistic } \\
\text { Chow - statistic with } 2 \text { states } \\
3 \text { regimes, and breaks in } 1977 \text { and } 1991\end{array}$ & $\begin{array}{r}0.969 \\
-7.024^{a} \\
12.330^{a}\end{array}$ & \\
\hline
\end{tabular}

$\overline{\bar{a}}$ sig 1\%

${ }^{b} \operatorname{sig} 5 \%$ 
Table 3: Elasticity of substitution, output growth and decomposition of labor productivity growth and skill-premium growth.

\begin{tabular}{lrrr|r}
\hline & Periods & & \\
& $1963: 1976$ & $1977: 1990$ & $1991: 2002$ & $1963: 2002$ \\
Substitution parameter ${ }^{1} \sigma$ & & & \\
\\
Decomposition of:
\end{tabular}

Notes: All figures except the elasticity of substitution are average annual percentage rates.

${ }^{1}$ The elasticity of substitution parameter is derived from the estimates of the ST Model as follows: $\sigma=-1 / \widehat{\gamma}_{1}$ in regime 1 and 3 and $\sigma=-1 /\left(\widehat{\gamma}_{1}+\widehat{\gamma}_{1, T_{77-91}}\right)$ in regime 2 .

Hats indicate estimates of the ST Model.

${ }^{2}$ The contribution of shifts is the average annual growth rate of:

$\left(\widehat{\gamma}_{2}+\widehat{\gamma}_{2, T_{91-02}} D_{T_{91-02}}\right) t+\left(\widehat{\gamma}_{3}+\widehat{\gamma}_{3, T_{77-91}} D_{T_{77-91}}\right) t^{2}$

The contribution of supply at constant elasticity of substitution is the average annual growth rate of $\widehat{\gamma}_{1} \ln \frac{S_{t}}{U_{t}}$.

The contribution of twists is: growth rate of $\widehat{\omega}_{s u, t}$ less the contribution of shifts and supply.

The contribution of errors is the average annual growth rate of the observed series less its estimates.

${ }^{3}$ The contribution of the respective factors are derived using the linear approximation:

$\frac{\Delta y}{y}=\frac{1}{y}\left(\frac{\partial g_{\sigma}}{\partial p} \Delta p+\frac{\partial g_{\sigma}}{\partial \widehat{b}} \Delta \widehat{b}+\frac{\partial g_{\sigma}}{\partial \widehat{\sigma}} \Delta \widehat{\sigma}\right)$ 

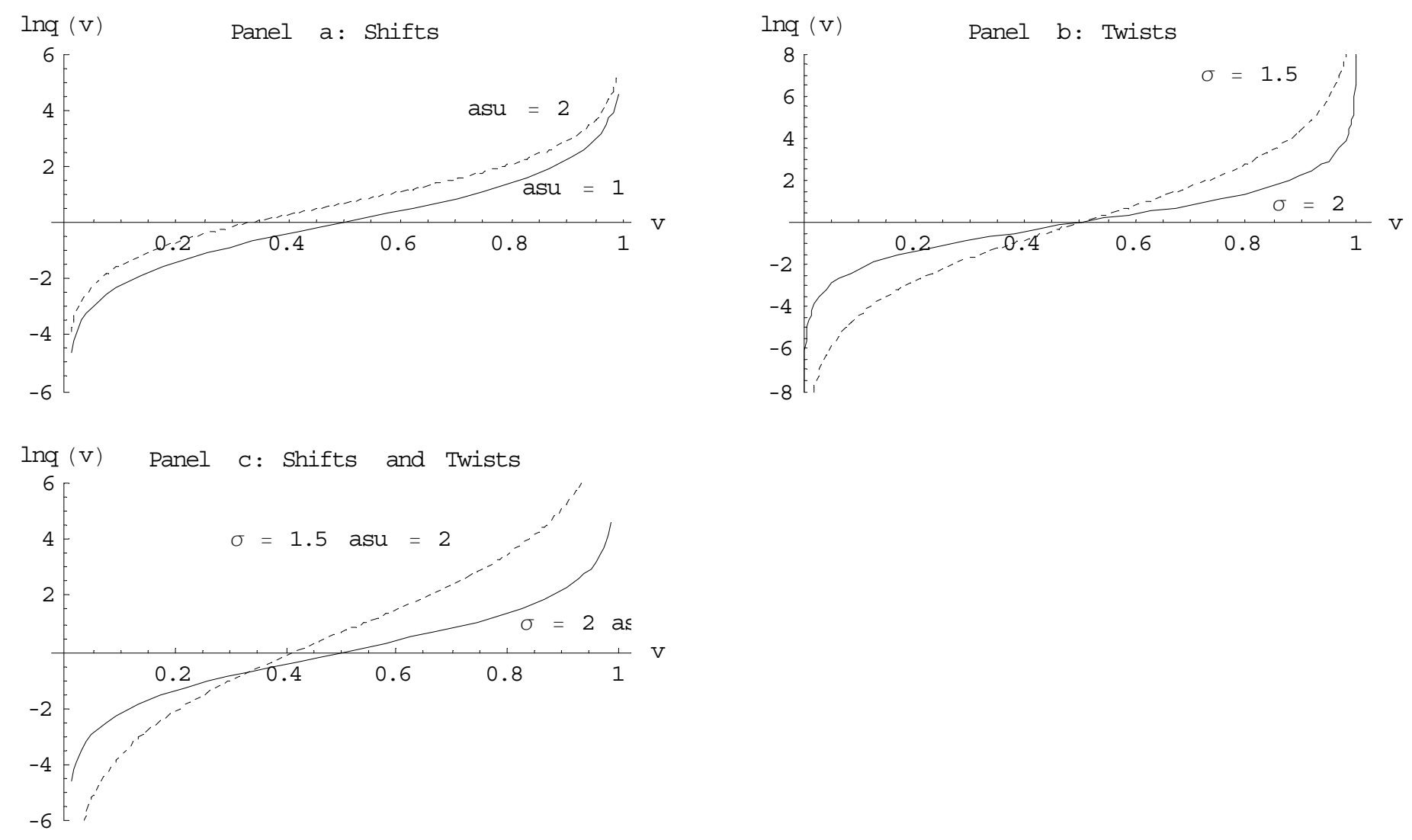

Figure 1: Shifts and twists in the relative productivity of skilled labor. 


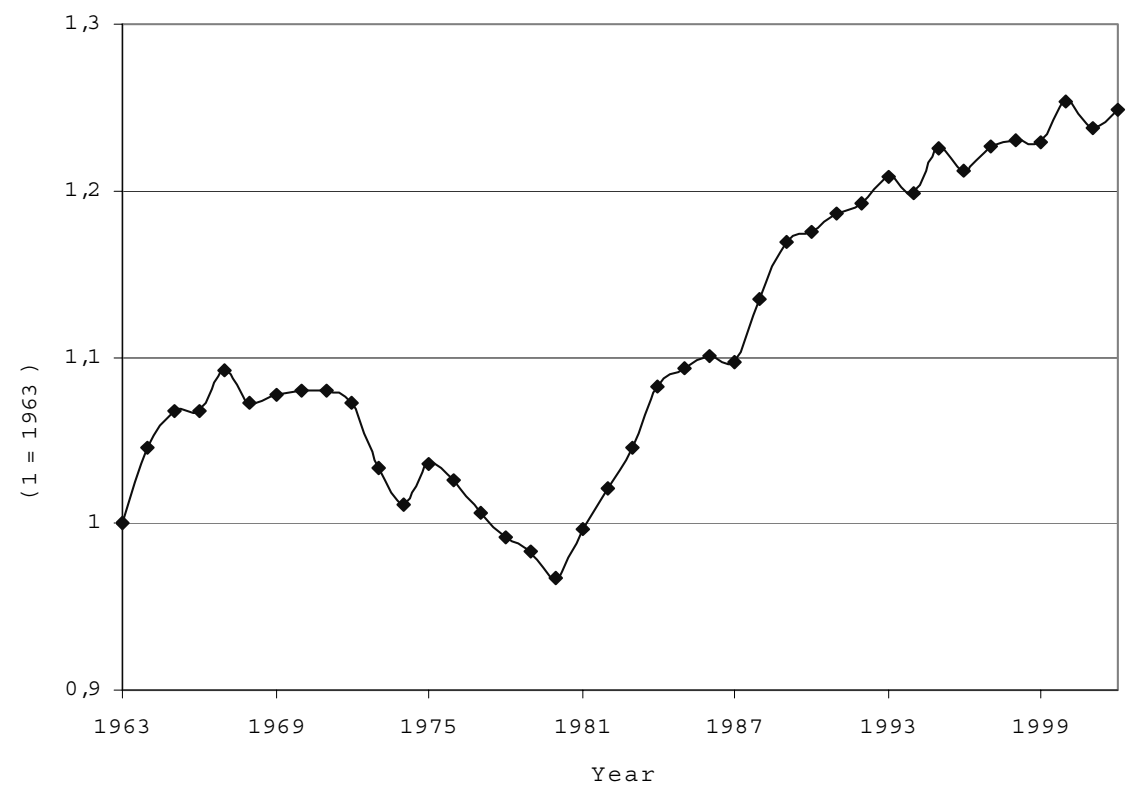

Figure 2: The skill premium: skilled vs. unskilled labor. 


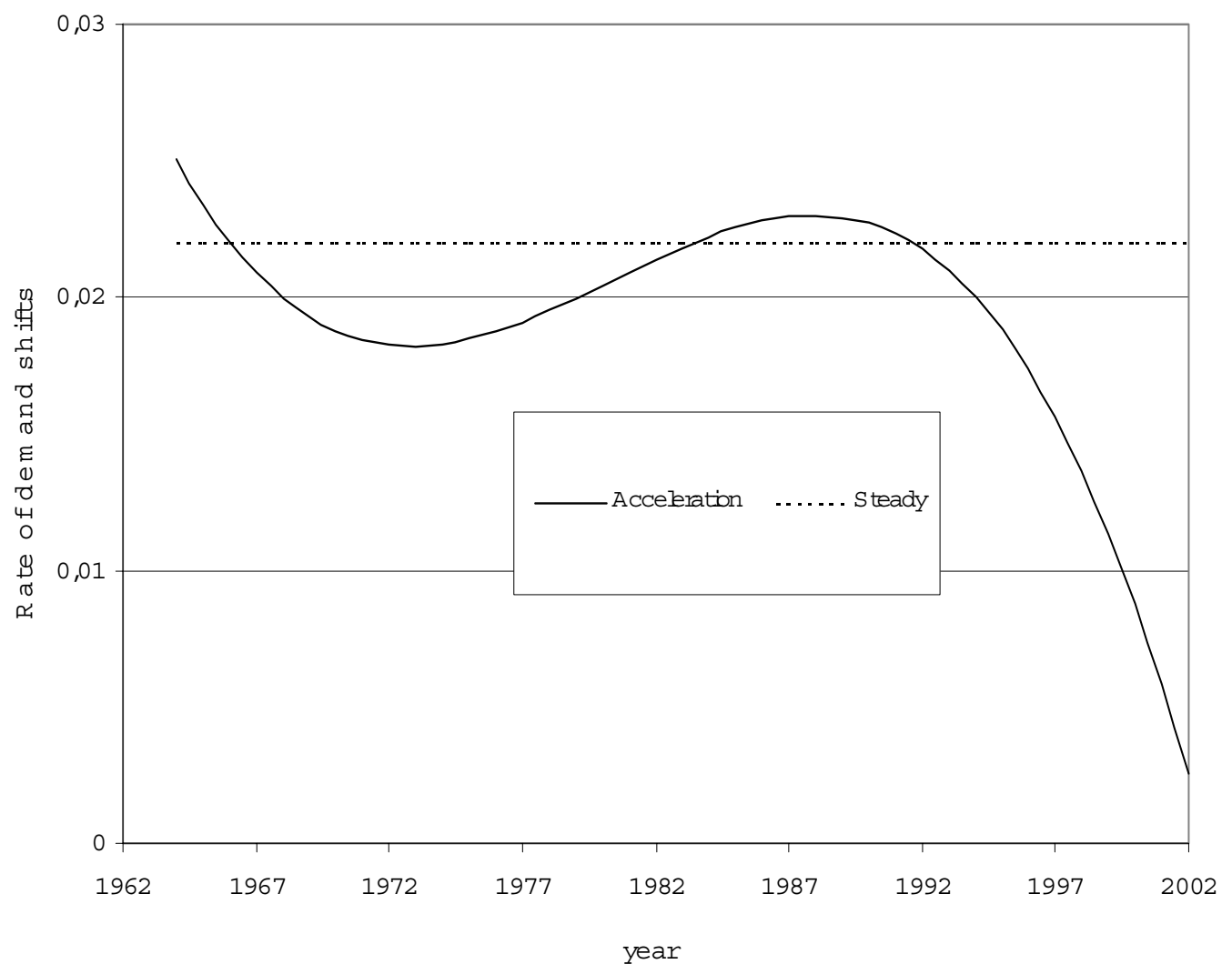

Figure 3: Acceleration or steady demand? 

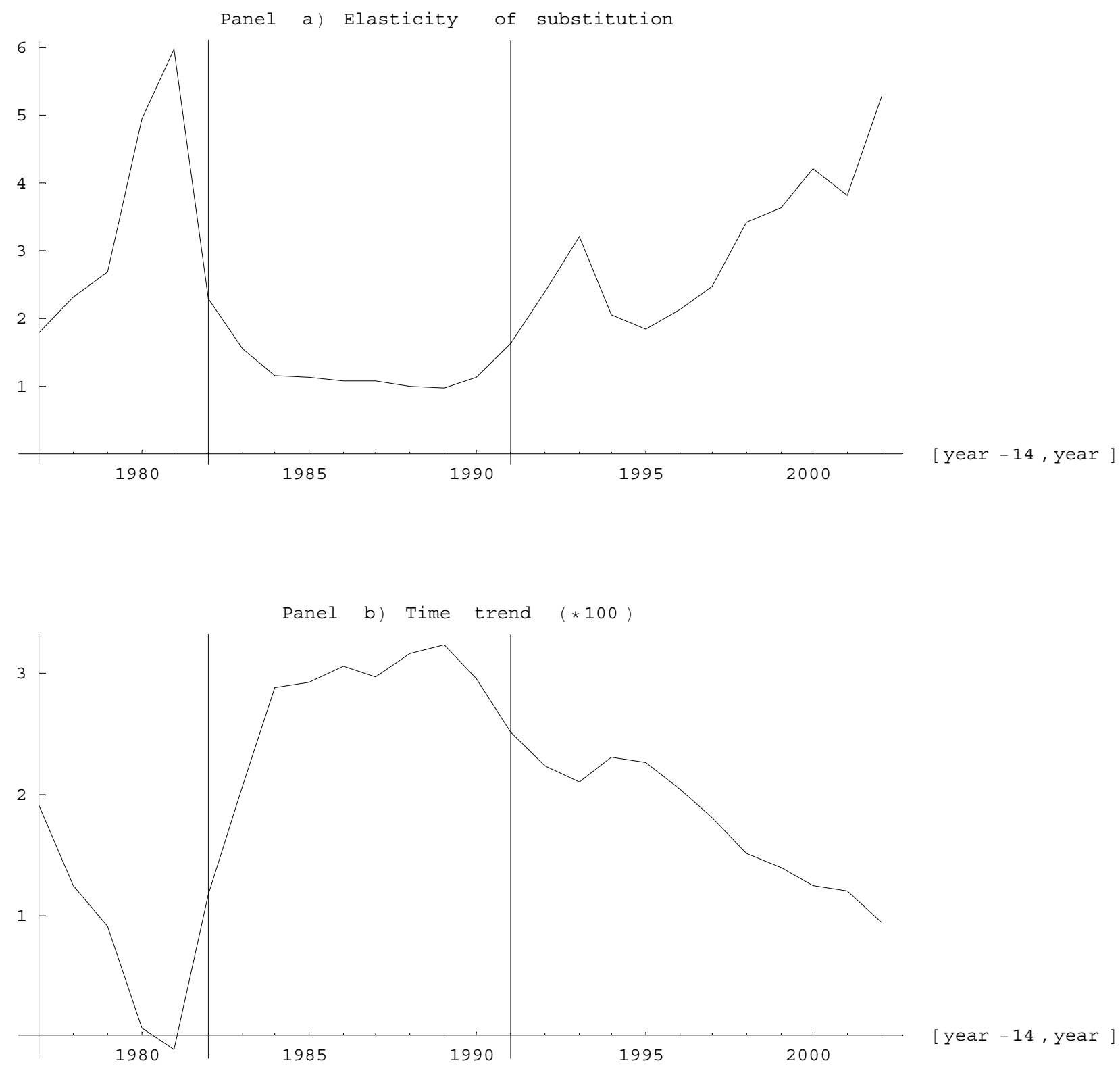

Figure 4: Stability of the parameters of the Katz and Murphy (1992) Model. Estimates derived using rolling regression techniques of sample size 15. 


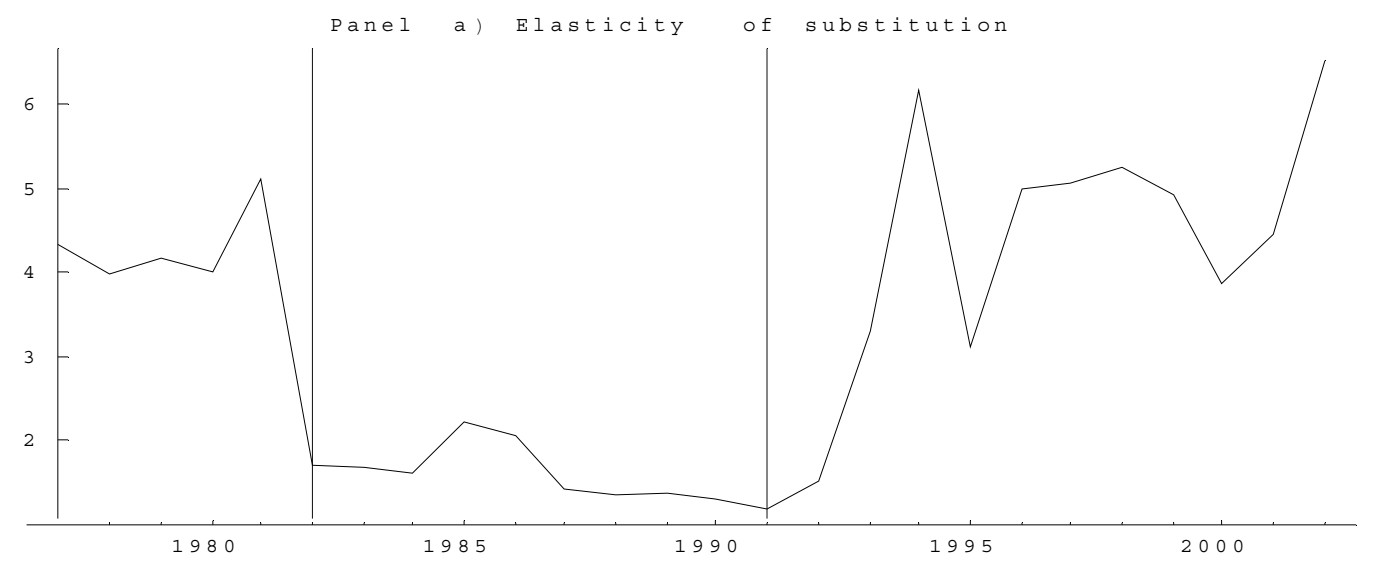

[ year-14, year ]

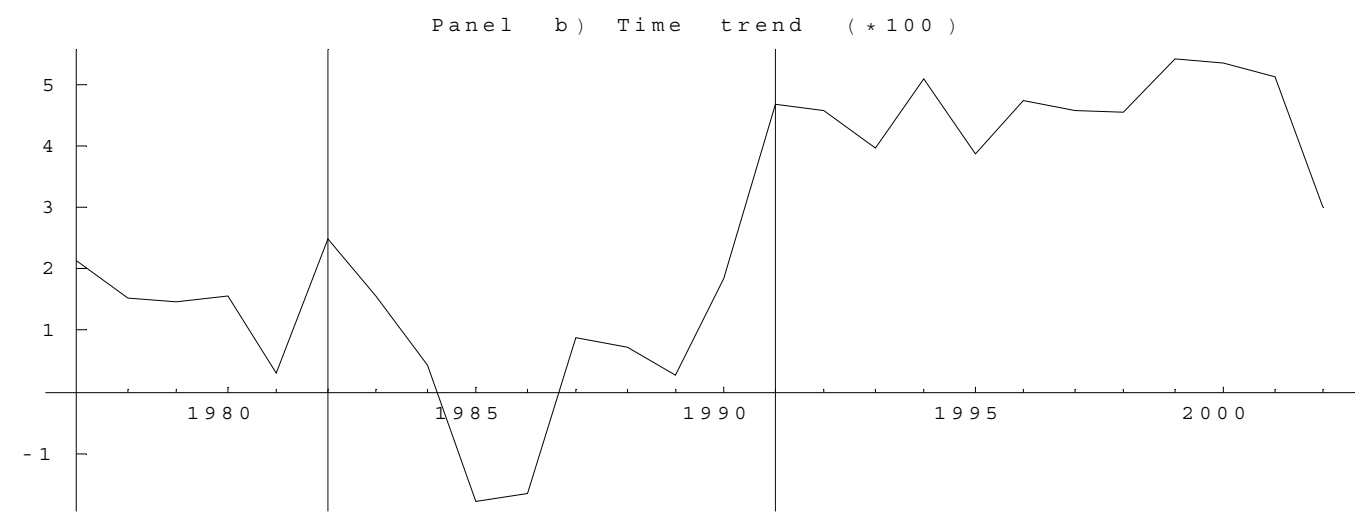

[ year-14, year]

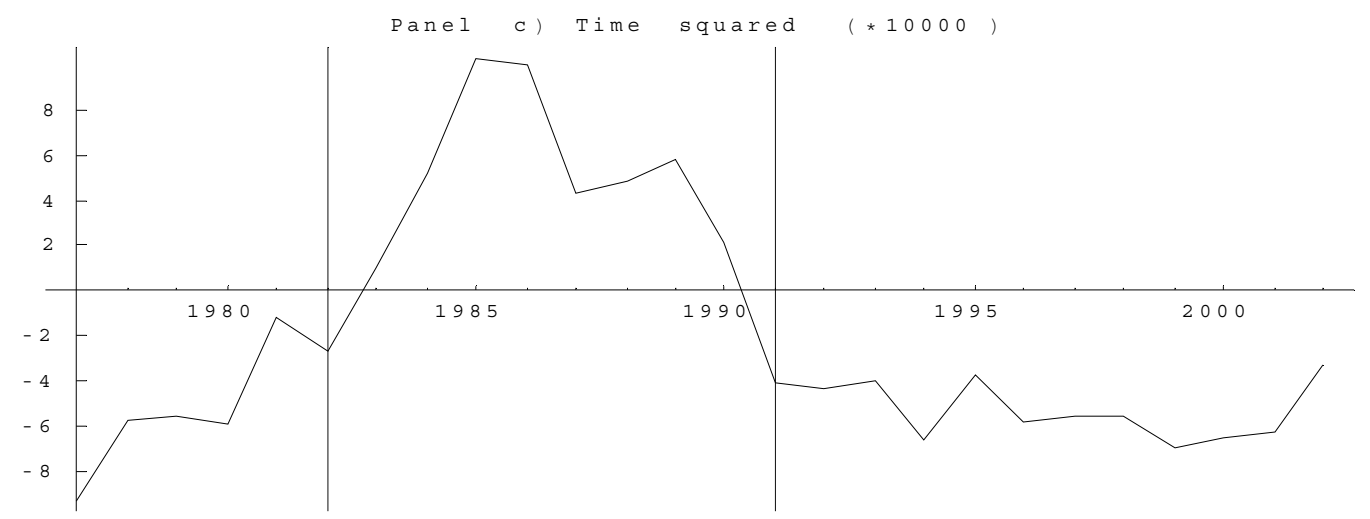

Figure 5: Stability of the parameters of the augmented Katz and Murphy (1992) Model. Estimates derived using rolling regression techniques of sample size 15. 